\title{
Physiological Responses of Dogs to Different Housing Systems
}

\author{
Esterina Fazio, Cristina Cravana, Antonio Giuliano \& Pietro Medica
}

\begin{abstract}
Background: The hypothalamic-pituitary-adrenal (HPA) axis undergoes adaptations throughout housing system that might contribute to the avoidance of adverse effects of welfare status in dogs housed in a shelter. Nevertheless, the influence of housing systems and stabling time on glucose and PCV changes is little known. The purpose of the present study was to evaluate the patterns of cortisol, glucose and PCV in dogs housed in a kennel and normal environments, evaluating the differences between housing systems, by taking into account the different stabling time and sex.

Materials, Methods \& Results: The study comprised 98 cross-breed dogs, aged $4 \pm 1.5$ years, lodged in a kennel (observational group I: $\mathrm{N}=61,29$ females and 27 males), in paired household dogs (control group II: $\mathrm{N}=25,13$ females and 12 males) and in unpaired household dogs (control group III: $\mathrm{N}=12,6$ females and 6 males). Females of both groups were spayed. The subjects were studied on the basis of different stabling times, ranged among $<1$ year, 2 years and 4 years, and different sex.

Discussion: This observational study showed that kennelled males lodged for $2(P<0.01)$ and $4(P<0.001)$ years showed lower cortisol concentrations than males lodged $<1$ year; males lodged for $<1$ year $(P<0.001)$ showed higher cortisol concentrations than females; males lodged for 4 year showed lower cortisol concentrations $(P<0.01)$ than females. Kennelled females lodged for 4 year showed higher PCV values $(P<0.001)$ than females lodged for $<1$ year. Paired and unpaired household females and males lodged for 4 years showed lower cortisol concentrations $(P<0.01)$ than 2 years and $<1$ year. Paired and unpaired household females and males lodged for short-, medium- and long-term times showed higher glucose concentrations $(P<0.001)$ than kennelled dogs. This study showed significant changes of circulating cortisol, glucose and PCV values inter- and intra-groups, according to different housing systems, stabling time and sex. The magnitude of cortisol decreases after 2 and 4 years of stabling time in kennelled male dogs could suggest a stimulus-response relationship, probably due to adaptive responses. Interestingly enough in this observational study was that the exact consummatory event could be represented by the long stabling time itself, observed only in males. Moreover, the significant differences of cortisol concentrations between males and females in group I after a stabling time of $<1$ and 4 years confirm the wide variability of HPA activity independent of the different sex of dogs. The physiological higher glucose concentrations in household dogs than kennel dogs showed that the normal home environment offers probably more rich stimuli than kennel, independent of stabling times and sex. It is possible to suppose that the housing system of dogs also results in significant rise of organ reserve and adaptability, presumably due at early greatest in functional changes in the catecholaminergic system and related increased hepatic glycogenolysis and gluconeogenesis. Concerning the PCV changes, data obtained confirmed the disagreement among authors about sex differences in the circulating mass of erythrocytes according to different age and sex. In conclusion, this is an observational study on the adaptive responses of circulating cortisol, glucose and PCV patterns to different housing systems in both kennel and household, leading to the question of physiological relevance concerning the effects of different stabling, according to the quality of dogs' life.
\end{abstract}

Keywords: dog, housing system, cortisol, glucose, packed cell volume. 


\section{INTRODUCTION}

Dog's adrenocortical activity is involved in response to social dynamics, hierarchical order and behavioural style [9], after loading, unloading and transport stress $[6,22,29]$. Significant changes in cortisol concentrations have been observed in a wide variety of coping strategies, through cortisol secretory patterns $[2,3,12,38]$ and corticoid:creatinine ratio [40]. Urinary cortisol:creatinine ratio was higher in the kennel than home environment and was not associated with differences in movement/exercise between environments [28]. The main stressors in a domestic dog encounter in a shelter are represented by isolation, exposure to constant noise and novelty, disrupted routines, irritating stimuli and the different admission time to kennels [4,8,14,30,39].

Few studies have been performed on the physiological changes of cortisol concentrations in dogs according to different biological sampling (saliva, urine, faeces, hair, blood) [1,7,13,28,41] or different non-invasive methods for evaluating stressful conditions $[27,34,42]$. The use of glucose in conjunction with cortisol determination may lend additional support to assess the HPA axis response to stress [29]. Comparison of stress indicators in blood of dogs after transportation and housing in the new environment [29], after competitions [32,33] and entering re-homing kennels [15] has been studied, but very little is also known about the influence of housing systems and stabling time on glucose and PCV changes.

The purpose of the present study was to evaluate the patterns of cortisol, glucose and PCV in dogs housed in a kennel and normal home environments, evaluating the differences between the two housing systems, by taking into account the different stabling time and sex.

\section{MATERIALS AND METHODS}

Study overview

All methods and procedures used in this experiment were in compliance with the guidelines of the Italian Health Minister for the care and use of animals (D.L. 4/3/2014 n. 26) and EU Directive (Directive 2010/63).

The study comprised 98 cross-breed dogs, aged $4 \pm 1.5$ years, lodged in a kennel (observational group I: $\mathrm{N}=61,29$ females and 27 males), in paired household dogs (control group II: $\mathrm{N}=25,13$ females and 12 males) and in unpaired household dogs (control group III: $\mathrm{N}=12,6$ females and 6 males). Females of both groups were spayed.

All subjects were fed once a day with a commercial feedstuff of "Trainer sterility" for spayed animals and "Trainer Acth" for uncastrated animals; water was available ad libitum.

The subjects were studied on the basis of different stabling times, ranged among $<1$ year, 2 years and 4 years, and different sex. Dogs of groups I were kept in a kennel comprised of two sections; an indoor section, represented by box ranged $4 \times 2 \mathrm{~m}^{2}$ and $6 \times 4$ $\mathrm{m}^{2}$, according to the number of dogs, equal to 2 and 5 ; and an outdoor section, respectively of $2 \times 3 \mathrm{~m}^{2}$ and $4 \mathrm{x}$ $4 \mathrm{~m}^{2}$, joined by a hatchway. These subjects have shown regular activities during the day as walking, playing, contact with other dogs and people (husbandry staff taking care, veterinarian).

Paired household dogs of group II and unpaired household dogs of group III were kept in normal home environments comprised of indoor section and they were taken for at least three walk per day of approximately $15 \mathrm{~min}$. The group II had contact and group III had no contact with other conspecifics at the home. On the basis of their history these subjects did no shown clinical signs or symptoms of disease or behavioural problems.

\section{Sample collection and processing}

Blood samples were collected once a day for two consecutive days by venipuncture of the cephalic vein, in basal conditions, at 09:00 a.m., under quiet conditions and placed into evacuated tubes (Venoject) ${ }^{1}$ and in K3-EDTA tubes (2.5 mL APTACA $)^{2}$ for PCV analysis. Evacuated tubes samples were subsequently (within $1 \mathrm{~h}$ ) centrifuged for $15 \mathrm{~min}$ at $1500 \mathrm{~g}$, serum was separated and glucose was immediately analyzed. The remaining part of serum was harvested and stored in polystyrene tubes at $-20^{\circ} \mathrm{C}$ until assayed for cortisol concentrations.

\section{Sample analysis}

Total serum cortisol concentrations were analysed in duplicate using a competitive enzyme immunoassay (EIA) ${ }^{3}$. During the first incubation, the cortisol sample competed with cortisol conjugated to horseradish peroxidase (HRP) for the specific sites of 
the antiserum coated on the wells. Following incubation, all unbound material was removed by aspiration and washing. The enzyme activity bound to the solid phase is inversely proportional to cortisol concentration in calibrators and samples and is made evident by incubating the wells with a chromogen solution (tetramethylbenzidine, TMB) in substrate-buffer. Colorimetric reading was carried out using a spectrophotometer at $450 \mathrm{~nm}$ wavelength (Sirio $\mathrm{S})^{3}$. Assay sensitivity was 5 $\mathrm{ng} / \mathrm{mL}$ and intra- and interassay CVs were $4.6 \%$ and $6.9 \%$ respectively.

Glucose concentrations were analysed using enzymatic colorimetric method (glucose oxidaseperoxidase-4-amminoantipyrine $)=(\text { GOD-POD-PAP })^{3}$. Assay sensitivity was $2 \mathrm{mg} / \mathrm{dL}$ and intra- and interassay CVs were $0.85 \%$ and $2.03 \%$ respectively.

To determine PCV values, 2 capillary tubes were filled from K3-EDTS tube and centrifuged in a microcapillary centrifuge for $5 \mathrm{~min}$; PCV value was the mean of the 2 capillary tubes.

\section{Statistical analysis}

Data are presented as means \pm standard deviation (S.D.). Student's t-test was applied to test the differences between housing groups, stabling times and sexes on cortisol, glucose and PCV changes. A linear correlation analysis (Pearson's method) was performed to analyse the relationships among physiological parameters. The level of significance was set at $P<0.05$. All calculations were performed using the PRISM package4.

\section{RESULTS}

Data obtained (Table 1) showed lower cortisol concentrations in kennelled males lodged for $2(P<$ $0.01)$ and $4(P<0.001)$ years than those $<1$ year, males lodged $<1$ year showed higher cortisol concentrations than females $(P<0.001)$; males lodged for 4 year showed lower cortisol concentrations $(P<0.01)$ than females.

Paired and unpaired household females and males lodged for 4 years showed lower cortisol concentrations $(P<0.01)$ than 2 years and $<1$ year.

Concerning the glucose values (Table 2), higher concentrations were observed in paired and unpaired household females and males $(P<0.001)$ lodged from $<1$ year to 4 years than kennelled dogs.

Concerning the PCV values (Table 3), kennelled females lodged from 4 years showed higher PCV values $(P<0.001)$ than $<1$ year.

No significant differences between cortisol and PCV of kennelled and household dogs were observed. No significant correlations among physiological parameters were observed.

Table 1. Circulating cortisol concentrations $(\mathrm{nmol} / \mathrm{L})$ in dogs of different sex and stabling time.

\begin{tabular}{|c|c|c|c|c|c|c|}
\hline \multirow{2}{*}{$\begin{array}{l}\text { Stabling } \\
\text { time }\end{array}$} & \multicolumn{2}{|c|}{ group I: kennel dogs } & \multicolumn{2}{|c|}{ group II: paired household dogs } & \multicolumn{2}{|c|}{ group III: unpaired household dogs } \\
\hline & q & $\hat{\sigma}$ & q & $\hat{\sigma}$ & q & $\hat{o}$ \\
\hline$<1$ year & $81.44 \pm 20.80$ & $154.47 \pm 14.18^{\mathrm{A}}$ & $97.39 \pm 24.96$ & $100.23 \pm 17.49$ & $87.19 \pm 20.16$ & $75.32 \pm 19.42$ \\
\hline 2 years & $99.98 \pm 35.08$ & $87.48 \pm 36.83^{\mathrm{a}}$ & $118.52 \pm 33.63$ & $99.21 \pm 33.53$ & $98.12 \pm 23.33$ & $93.41 \pm 23.13$ \\
\hline 4 years & $106.16 \pm 33.57$ & $54.60 \pm 21.57^{\mathrm{bB}}$ & $52.89 \pm 18.95^{\mathrm{a}}$ & $51.45 \pm 28.44^{\mathrm{a}}$ & $55.80 \pm 19.55^{\mathrm{a}}$ & $53.65 \pm 18.63^{\mathrm{a}}$ \\
\hline
\end{tabular}

vs $<1$ year: $\mathrm{a}=P<0.01 ; \mathrm{b}=P<0.001 ;$ vs $q \mathrm{~A}=P<0.001 ; \mathrm{B}=P<0.01$.

Table 2. Circulating glucose concentrations $(\mathrm{mg} / \mathrm{dL})$ in dogs of different sex and stabling time.

\begin{tabular}{|c|c|c|c|c|c|c|}
\hline \multirow{2}{*}{$\begin{array}{l}\text { Stabling } \\
\text { time }\end{array}$} & \multicolumn{2}{|c|}{ group I: kennel dogs } & \multicolumn{2}{|c|}{ group II: paired household dogs } & \multicolumn{2}{|c|}{ group III: unpaired household dogs } \\
\hline & $q$ & o & 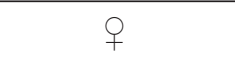 & o & $q$ & o \\
\hline$<1$ year & $51.10 \pm 13.79$ & $58.66 \pm 9.71$ & $79.20 \pm 7.19 *$ & $88.25 \pm 7.41 *$ & $82.22 \pm 7.58 *$ & $81.65 \pm 7.36^{*}$ \\
\hline 2 years & $61.43 \pm 15.37$ & $57.57 \pm 20.87$ & $87.75 \pm 15.97 *$ & $78.50 \pm 12.07 *$ & $87.75 \pm 15.97 *$ & $80.56 \pm 11.17 *$ \\
\hline 4 years & $64.33 \pm 15.73$ & $59.33 \pm 15.63$ & $85.50 \pm 19.19 *$ & $87.75 \pm 20.65^{*}$ & $85.00 \pm 19.11^{*}$ & $88.77 \pm 22.30 *$ \\
\hline
\end{tabular}


Table 3. PCV (\%) values in dogs of different sex and stabling time.

\begin{tabular}{|c|c|c|c|c|c|c|}
\hline \multirow{2}{*}{$\begin{array}{l}\text { Stabling } \\
\text { time }\end{array}$} & \multicolumn{2}{|c|}{ group I: kennel dogs } & \multicolumn{2}{|c|}{ group II: paired household dogs } & \multicolumn{2}{|c|}{ group III: unpaired household dogs } \\
\hline & $q$ & 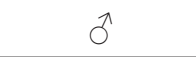 & $q$ & $\hat{\jmath}$ & q & $\hat{0}$ \\
\hline$<1$ year & $44.75 \pm 5.57$ & $51.25 \pm 2.98$ & $50.60 \pm 3.21$ & $50.00 \pm 5.48$ & $50.05 \pm 3.21$ & $45.20 \pm 3.48$ \\
\hline 2 years & $49.36 \pm 6.10$ & $50.85 \pm 4.79$ & $49.50 \pm 3.79$ & $45.25 \pm 4.43$ & $48.56 \pm 3.17$ & $47.22 \pm 3.13$ \\
\hline 4 years & $57.22 \pm 6.18^{\mathrm{a}}$ & $55.20 \pm 5.09$ & $51.00 \pm 2.82$ & $47.00 \pm 2.58$ & $49.00 \pm 2.66$ & $48.00 \pm 2.68$ \\
\hline
\end{tabular}

\section{DISCUSSION}

Circulating cortisol concentrations obtained in dogs of groups I and II are in agreement with data reported in literature for domestic dog (Canis familiaris) [11,17].

The magnitude of cortisol decreases after 2 and 4 years of stabling time in kennelled male dogs could suggest a stimulus-response relationship, probably due to adaptive responses. Moreover, circumstantial evidence suggests that during the greatest stabling time males had presumably become totally accustomed to kennel environment; this response could be related to the possible inhibition of adrenocortical activity, reported when the presentation of stressful stimulus involves a consummatory event [23]. On this basis, these data suggest that stabling time might induce an activation of the HPA with an increase in cortisol concentrations only in dogs lodged from $<1$ year, as previously observed by Mondelli et al. [24] that to consider the cortisol concentration of dogs lodged from 2 years in a shelter a baseline value references.

Interestingly enough in this observational study was that the exact consummatory event could be represented by the long stabling time itself, observed only in males. However, the fact that the cortisol trend differs between females and males, fortunately does not precludes the possibility to compare the two different sex, establishing if sex had a real impact on cortisol changes. Indeed, a significant effect of sex on cortisol changes only in males lodged from both $2(P<0.01)$ and $4(P<0.001)$ years was observed. Moreover, the significant differences of cortisol concentrations between males and females in group I after a stabling time of $<1$ and 4 years confirm the wide variability of HPA activity independent of the different sex of dogs [20].

On the other hand, it is possible to suppose that normal home environment could have elide this effect, as demonstrate by the absence of significant dif- ferences in cortisol concentrations in household male and female dogs, independent of short-, medium- and long-term stabling times. There are several possible explanations as why no significant differences were observed. The first is that stress responses to normal home environment change, over the short- and medium time, remain reasonably constant throughout homing, showing that once dogs were habituated to their circumstance. The second is that this previous level of habituation probably increased with long-time and with relative previous experience of homed dogs, as shown by the lowest cortisol concentrations in dogs stabling for 4 years. Hence, the third possibility is that the length of time in normal home environment is a major determinant of welfare state for dogs.

The results obtained do not exclude that certain stressful conditions, as a visit to a veterinary practice or hospitalization in a referral clinic [40], immobilization stress [9], novel stimuli and social isolation [8,25,36], entering and re-homing kennels [15] may disrupt the pituitary-axis in domestic dogs and lead to an increase in cortisol concentrations.

Therefore, the different adrenocortical response between groups I and II could be interpreted in terms of different physical and mental stimuli. This consideration seems likely, since the environmental stimuli (familiar and/or unfamiliar) are associated with changes in HPA sensitivity [16]. In addition, a circadian cortisol rhythm was observed in dogs with common daily routine with no particular physical and emotional load and in experimental dogs used for experimental purpose on a long-term basis [20]. Likewise, in previous study dogs confined in the shelter for their 1st, 2nd, or 3rd day had higher cortisol levels than a group maintained for more than 9 days; in addition, dogs in the shelter for an intermediate period (day 4-9) had intermediate levels of cortisol [14].

Concerning the age variability, the effects of aging on the HPA system in response to challenge 
by stress were specifically investigated also in dogs [31]. Younger dogs had higher cortisol concentrations than older ones; hence, adult males maintained relatively low cortisol concentrations [9]. In this study the age of dogs stabled from short-term time was the same of subjects stabled from medium- or long-term time.

On this basis, part of the difficulty in determining the role played by the stabling time in stress responses is caused by the fact that circulating cortisol concentrations could not reflect the existence of circadian rhythms, because minute by minute fluctuations in plasma cortisol concentrations could only be observed if more frequent blood samplings were employed $[18,20,26]$. However, this consideration has not been tested experimentally. Certainly, the presence or absence of a circadian rhythm cannot be ascribed to the time of day, since all blood samplings for the different groups were performed at 09:00 $\mathrm{h}$.

The physiological higher glucose concentrations in household dogs than kennel dogs showed that the normal home environment offers probably more rich stimuli than kennel, independent of stabling times and sex. It is possible to suppose that the housing system of dogs also results in significant rise of organ reserve and adaptability, presumably due at early greatest in functional changes in the catecholaminergic system and related increased hepatic glycogenolysis and gluconeogenesis [10].
Concerning the PCV changes, there is disagreement among authors about gender differences in the circulating mass of erythrocytes according to different age [19,21] and sex [5,35,37].

\section{CONCLUSION}

In conclusion, this is an observational study on the adaptive responses of circulating cortisol, glucose and PCV patterns to different housing systems in both kennel and household, leading to the question of physiological relevance concerning the effects of different stabling time in dogs, according to the quality of life.

\author{
MANUFACTURERS \\ ${ }^{1}$ Terumo Corp. Leuven, Belgium. \\ ${ }^{2}$ APTACA s.r.l. Canelli, Ialy. \\ ${ }^{3}$ SEAC/RADIM. Florence, Italy. \\ ${ }^{4}$ GraphPad Software Inc. San Diego, CA, USA.
}

Acknowledgements. We would like to thank the veterinarian Dr. Antonio Giuliano for his assistance with data and blood sample collection.

Ethical approval. All procedures were formally approved by Ethical Committee for the care and use of animals of Department of Veterinary Sciences and were performed in compliance with the guidelines of the Italian law on the care and use of animals (D.L. 4/3/2014 n. 26) and EU Directive (Directive 2010/63).

Declaration of interest. The authors declare that they have no conflict of interest that could be perceived as prejudicing the impartiality of the research reported.

\section{REFERENCES}

1 Accorsi P.A., Carloni E., Valsecchi P., Viggiani R., Gamberoni M., Tamanini C. \& Seren E. 2008. Cortisol determination in hair and faeces from domestic cats and dogs. General and Comparative Endocrinology. 155(2): 398-402.

2 Beerda B., Schilder M.B.H., van Hooff J.A.R.A.M. \& de Vries H.W. 1997. Manifestations of chronic and acute stress in dogs. Applied Animal Behavior Science. 52(3-4): 307-319.

3 Beerda B., Schilder M.B.H., van Hooff J.A.R.A.M., de Vries H.W. \& Mol J.A. 1998. Behavioural, saliva cortisol and heart rate responses to different types of stimuli in dogs. Applied Animal Behavior Science. 58(3-4): 365-381.

4 Beerda B., Schilder M.B.A., van Hoof J.A.R.A.M., de Vries H.W. \& Mol J.A. 2000. Behavioural and hormonal indicators of enduring environmental stress in dogs. Animal Welfare. 9(1): 49-62.

5 Bell G.M. \& Fowler J.S. 1985. Red cell population distributions in healthy dogs. Research in Veterinary Science. 38(2): 220-225.

6 Bergeron R., Scott S.L., Émond J.P., Mercier F., Cook N.J. \& Schaefer A.L. 2002. Physiology and behavior of dogs during air transport. Canadian Journal of Veterinary Research. 66(3): 211-216.

7 Bryan H.M., Adams A.G., Invik R.M., Wynne-Edwards K.E. \& Smits J.E.G. 2013. Hair as a meaningful measure of baseline cortisol levels over time in dogs. Journal of the American Association for Laboratory Animal Science. 52(2): 189-196.

8 Coppola C.L., Grandin T. \& Enns R.M. 2003. Effect of temperament on stress response of stray adult dogs in a shelter environment. Journal of Animal Science. 81(Supp11): 69. 
9 de Villiers M.S., van Jaarsveld A.S., Meltzer D.G. \& Richardson P.R. 1997. Social dynamics and the cortisol response to immobilization stress of the African wild dog, Lycaon pictus. Hormones and Behavior. 31(1): 3-14.

10 Desborough J.P. 2000. The stress response to trauma and surgery. British Journal of Anaesthesia. 85(1): 109-117.

11 Feldman B.F., Zinkl J.G., Jain N.C. \& Schalm O.W. 2000. Schalm's Veterinary Hematology. 5th edn. Philadelphia: Lippincott Williams \& Wilkins, 356p.

12 Gazzano A., Mariti C., Himmelmann M., Calderisi L., Niccolini A., Ruggeri G., Guidi G., Ducci M., Martelli F. \& Sighieri C. 2004. Evaluation of cortisolemia in dogs housed in a shelter. Annali Facoltà Medicina Veterinaria Pisa. LVII(2): 189-196.

13 Grigg E.K., Nibblett B.M., Robinson J.Q. \& Smits J.E. 2017. Evaluating pair versus solitary housing in kennelled domestic dogs (Canis familiaris) using behaviour and hair cortisol: a pilot study. Veterinary Record Open 4(1):e000193. doi:10,1136/vetreco-2016-000193

14 Hennessy M.B., Davis H.N., Williams M.T., Mellott C. \& Douglas C.W. 1997. Plasma cortisol levels of dogs at a county animal shelter. Physiology \& Behavior. 62(3): 485-490.

15 Hiby E.F., Rooney N.J. \& Bradshaw J.W. 2006. Behavioural and physiological responses of dogs entering re-homing kennels. Physiology \& Behavior. 89(3): 385-391.

16 Irvine C.H.G. \& Alexander S.L. 1994. Factors affecting the circadian rhythm in plasma cortisol concentrations in the horse. Domestic Animals Endocrinology. 11(2): 227-236.

17 Kaneko J., Harney J.W. \& Bress M.L. 2010. Blood analyte reference values in small and same laboratory animals (Appendix IX). In: Clinical Biochemistry of Domestic Animals. San Diego: Academic Press, 896p.

18 Kemppainen R.J. \& Sartin J.L. 1984. Effects of a single intravenous dose of dexamethasone on baseline plasma cortisol concentrations and responses to synthetic ACTH in healthy dogs. American Journal of Veterinary Research. 45(4): 742-746.

19 Kimura T., Ohshima S. \& Doi K. 1992. Haematological and serum biochemical values in hairless and haired descendants of Mexican hairless dogs. Laboratory Animals. 26(3): 214-218.

20 Kolevská J., Brunclík V. \& Svoboda M. 2003. Circadian rhythm of cortisol secretion in dogs of different daily activities. Acta Veterinaria Brno. 72(4): 599-605.

21 Konrád J., Cupák M. \& Husák S. 1980. Hematology of the clinically healthy dog. Veterinární Medicína (Praha). 25(7): 405-412.

22 Leadon D.P. \& Mullins E. 1991. Relationship between kennel size and stress in greyhounds transported short distances by air. Veterinary Record. 129(4): 70-73.

23 Levine S., Coe C. \& Wiener S. 1989. Psychoneuroendocrinology of stress: a psychobiological perspective. In: Brush F.R. \& Levine S. (Eds). Psychoneuroendocrinology. New York: Academic Press Inc, pp.341-377.

24 Mondelli, F., Prato Previde E., Verga M., Levi D., Magistrelli S. \& Valsecchi F. 2004. The bond that never developed: adoption and relinquishment of dogs in a rescue shelter. Journal of Applied Animal Welfare Science. 7(4): 253-266.

25 Muir J.L. \& Pfister H.P. 1986. Corticosterone and prolactin responses to predictable and unpredictable novelty stress in rats. Physiology \&. Behavior. 37(2): 285-288.

26 Orth D.N., Peterson M.E. \& Drucker W.D. 1998. Plasma immunoreactive proopiomelanocortin peptides and cortisol in normal dogs and dogs with Cushing's syndrome: diurnal rhythm and responses to various stimuli. Endocrinology. 122(4): 1250-1262.

27 Palme R., Schatz S. \& Möstl E. 2001. Effect of vaccination on fecal cortisol metabolites in cats and dogs. Deutsche Tierärztliche Wochenschrift. 108(1): 23-25.

28 Part C.E., Kiddie J.L., Hayes W.A., Mills D.S., Neville R.F., Morton D.B. \& Collins L.M. 2014. Physiological, physical and behavioural changes in dogs (Canis familiaris) when kennelled: testing the validity of stress parameters. Physiology \& Behavior. 133(11): 260-271.

29 Radisavljević K., Vučinić M., Becskei Zs., Stanojković A. \& Ostović M. 2017. Comparison of stress level indicators in blood of free-roaming dogs after transportation and housing in the new environment. Journal of Applied Animal Research. 45(1): 52-55.

30 Rooney N.J., Gaines S.A. \& Bradshaw J.W. 2007. Behavioural and glucocorticoid responses of dogs (Canis familiaris) to kennelling; investigating mitigation of stress by prior habituation. Physiology \& Behavior. 92(5): 847-854. 
31 Rothuizen J., Reul J.M., van Sluijs F.J., Mol J.A., Rijnberk A. \& de Kloet E.R. 1993. Increased neuroendocrine reactivity and decreased rain mineralcorticoid receptor-binding capacity in aged dogs. Endocrinology. 132(1): 161-168.

32 Rovira S., Muñoz A. \& Benito M. 2007. Hematologic and biochemical changes during canine agility competitions. Veterinary Clinical Pathology. 36(1): 30-35.

33 Rovira S., Muñoz A. \& Benito M. 2007. Fluid and electrolyte shifts during and after agility competitions in dogs. The Journal of Veterinary Medical Science. 69(1): 31-35.

34 Schatz S. \& Palme R. 2001. Measurement of faecal cortisol metabolites in cats and dogs: a non-invasive method for evaluating adrenocortical function. Veterinary Research Communications. 25(4): 271-287.

35 Shiel R.E., Brennan S.F., O'Rourke L.G., McCullough M. \& Mooney C.T. 2007. Hematologic values in young pretraining healthy Greyhounds. Veterinary Clinical Pathology. 36(3): 274-277.

36 Stephen J.M. \& Ledger R.A. 2005. An audit of behavioural indicators of poor welfare in kennelled dogs in the United Kingdom. Journal of Applied Animal Welfare Science. 8(2): 79-96.

37 Swanson K.S., Kuzmuk K.N., Schook L.B. \& Fahey G.C. 2004. Diet affects nutrient digestibility, hematology, and serum chemistry of senior and weanling dogs. Journal of Animal Science. 82(6): 1713-1724.

38 Titulaer M., Blackwell E.J., Mendl M. \& Casey R.A. 2013. Cross sectional study comparing behavioural, cognitive and physiological indicators of welfare between short and long term kennelled domestic dogs. Applied Animal Behavior Science. 147(1): 149-158.

39 Tuber D.S., Miller D.D., Caris K.A., Halter R., Linden F. \& Hennessy M.B. 1999. Dogs in animal shelters; problems, suggestion, and needed expertise. Psychological Science. 10(5): 379-386.

40 van Vonderen I.K., Kooistra H.S. \& Rijnberk A. 1998. Influence of veterinary care on the urinary corticoid:creatinine ratio in dogs. Journal of Veterinary Internal Medicine. 12(1): 431-435.

41 Vincent I.C. \& Michell A.R. 1992. Comparison of cortisol concentrations in saliva and plasma of dogs. Research in Veterinary Science. 53(3): 342-345.

42 Young K.M., Walker S.L., Lanthier C., Waddell W.T., Monfort S.L. \& Brown J.L. 2004. Noninvasive monitoring of adrenocortical activity in carnivores by fecal glucocorticoid analyses. General and Comparative Endocrinology. 137(2): 148-165. 